\title{
Formação de professores e educação de surdos: revisão sistemática de teses e dissertações
}

\author{
Melaine Duarte Ribeiro Muttão \\ Universidade de São Paulo - Ribeirão Preto - SP - Brasil \\ Ana Claudia Balieiro Lodi \\ Universidade de São Paulo - Ribeirão Preto - SP - Brasil
}

\begin{abstract}
Resumo
As décadas de 1990 e 2000 foram marcadas pela publicação de diversos documentos internacionais e nacionais que influenciaram as atuais políticas educacionais de nosso país. Por meio delas, foi instituído um novo olhar para educação especial, que deixou de ser pensada de forma paralela ao sistema comum e passou a integrar a proposta pedagógica da escola regular. Como consequência, a formação de professores para a educação básica também precisou ser revista. Neste contexto, o presente trabalho teve como objetivo compreender como a formação de professores para a educação de surdos foi discutida em teses e dissertações no período de 1995 a 2014. Constitui-se, portanto, em uma pesquisa bibliográfica que adotou, como procedimento metodológico, a Revisão Sistemática da Literatura. Para o acesso aos trabalhos, foi realizada uma busca online nas bibliotecas de Programas de Pós-graduação em Educação, avaliados pelas CAPES com conceito igual ou superior a cinco. Foram encontradas 35 pesquisas, escritas entre os anos de 2009 e 2014. A análise dos estudos apontou para a discussão e reflexão de dois grandes períodos: do que trata das extintas habilitações específicas em Educação de Deficientes da Audiocomunicação e do que discute uma nova configuração de formação do professor, regente e especialista. Conclui-se que, para a maioria dos estudos, as especificidades da educação de surdos não têm sido contempladas na formação inicial, ao restringir a formação do professor à disciplina Libras. Esta realidade tem demandado dos professores a busca por formação continuada, foco da maioria das pesquisas.
\end{abstract}

Palavras-chave: Formação de professores; Educação Especial; Pós-graduação.

\section{Teacher training and education of deaf: systematic review of theses and dissertations}

\begin{abstract}
The 1990s and 2000s were marked by the publication of several international and national documents that influenced the current educational policies of our country. Through them, a new look for special education was instituted, which ceased to be thought in parallel with the common system and began to integrate the pedagogical proposal of the regular school. As a consequence, teacher training for basic education also needed to be reviewed. In this context, the present study aimed to understand how teacher training for the education of the deaf was discussed in theses and dissertations from 1995 to 2014 . It is therefore a bibliographical research that adopted, as a methodological procedure, the Systematic Review of Literature. For access to the works, an online search was carried out in the libraries of Postgraduate Education Programs, evaluated by CAPES with a concept equal to or greater than five. Thirty-five research papers written between the years of 2009 and 2014 were found. The analysis of the studies pointed to the discussion and reflection of two major periods: of what deals with the extinct specific qualifications in Education of the Deficient of the Audio communication and what discusses a new configuration teacher training, regent and specialist. It is concluded that, for most studies, the specificities of the education of the deaf have not been contemplated in the initial formation, by restricting the teacher's formation to the discipline Libras. This reality has demanded from the teachers the search for continuing education, the focus of most research.
\end{abstract}

Keywords: Teacher training; Special Education; Postgraduate studies.

\section{Formación de profesores y educación de sordos: revisión sistemática de tesis de}

\section{maestría y de doctorado}

\section{Resumen}

Las décadas de 1990 y 2000 fueran marcadas por la publicación de diversos documentos internacionales y nacionales que influenciaron las actuales políticas educacionales de nuestro país. Por intermedio de ellas, se instituyó una nueva mirada a la educación especial, que dejó de ser pensada de forma paralela al sistema común y pasó a integrar la propuesta pedagógica de la escuela regular. Como consecuencia, la formación de profesores para la educación básica también necesitó ser revisada. En este contexto, el presente estudio tuvo como objetivo comprender como la formación de profesores para la educación de sordos fue discutida en tesis de maestría y de doctorado en el período de 1995 a 2014. Se constituye, por lo tanto, en una investigación bibliográfica que adoptó, como procedimiento metodológico, la Revisión Sistemática de la Literatura. Para el acceso a los estudios, se realizó una búsqueda online en las bibliotecas de Programas de Pos graduación en Educación, evaluados por las CAPES con concepto igual o superior a cinco. Se encontró 35 estudios, escritos entre los años de 2009 y 2014 . El análisis 
de los estudios apuntó para la discusión y reflexión de dos grandes períodos: de lo que trata de las extintas habilitaciones específicas en Educación de Deficientes del Audio comunicación y de lo que discute una nueva configuración de formación del profesor, regente y especialista. Se concluye que, para la mayor parte de los estudios, las especificidades de la educación de sordos no han sido contempladas en la formación inicial, al restringir la formación del profesor a la asignatura Libras. Esta realidad ha demandado de los profesores la búsqueda por formación continuada, enfoque de la mayorparte de las investigaciones.

Palabras clave: Formación de profesores; Educación Especial; Pos graduación.

\section{Introdução}

Durante séculos a formação de professores para a educação de surdos não foi uma preocupação em nosso país. Foi apenas na década de1970 que as habilitações específicas para a área da educação especial passaram a ser oferecidas nos cursos de Pedagogia e entre elas, aquela voltada à educação de surdos - habilitação em Educação de Deficientes da Audiocomunicação (EDAC). O objetivo desta formação era a de que o professor habilitado garantisse condições para que o aluno tivesse um bom desenvolvimento da linguagem oral, base para que as disciplinas escolares fossem ministradas da mesma forma como se trabalhava com crianças ouvintes (Pereira, 2000). Assim, o foco da formação de professores para surdos priorizava práticas terapêuticas de treinamento auditivo e de reabilitação da fala no atendimento ao surdo em detrimento das educacionais, buscando-se por meio delas, sua normalização.

Essa situação continuou ainda na década de 1990, período em que começaram os estudos sobre a Língua Brasileira de Sinais (Libras), discussões sobre a educação bilíngue para surdos, já implantada, desde a década anterior, em países da Europa, da América do Sul e nos Estados Unidos, e publicações de documentos internacionais que reconheciam a educação bilíngue como um direito das pessoas surdas, como a Declaração de Salamanca, que teve grande influência na elaboração das políticas educacionais de nosso país.

Dois anos após esta Declaração, foi publicada a nova Lei de Diretrizes e Bases da Educação Nacional (LDB). Nesta, assim como na LDB de 1961 (Lei $n^{\circ} 4.024,1961$ ), foi dedicado um capítulo à Educação Especial, entendida como uma modalidade de educação escolar ofertada, preferencialmente, na rede regular de ensino. Assim, em diálogo com a Constituição Federal, não há nela a defesa de "um modelo único de educação e, portanto, a inclusão de todos os alunos, de maneira indiscriminada, nas redes regulares" (Lodi, 2014, p.277), reconhecendo que, para algumas crianças, este não é o melhor modelo de ensino (por isso preferencial). Assegura, ainda, para a educação de alunos com deficiência, grupo em que estão inseridos os surdos nas legislações nacionais, "professores com especialização adequada em nível médio ou superior, para atendimento especializado, bem como professores do ensino regular capacitados para a integração desses educandos nas classes comuns" (Lei n. ${ }^{\circ} 9.394,1996$, Artigo 59, Inciso III. Ênfase adicionada). No entanto, no Título VI da Lei, que trata especificamente "Dos Profissionais da Educação", não há menção a como haverá a capacitação desses profissionais.

A partir da LDB, outros documentos foram publicados visando atender ao que nela foi disposto, como por exemplo, a Resolução do Conselho Nacional de Educação/Câmara de Educação Básica (CNE/CEB) no 02/2001, que em seus Artigos $2^{\circ}$ e $3^{\circ}$, determina a matricula de todos os alunos nos sistemas de ensino, cabendo às escolas organizarem-se para o atendimento aos educandos com deficiência, assegurando as condições necessárias para a escolarização de todos, bem como uma proposta pedagógica que assegure recursos e serviços educacionais especiais. No que se refere aos professores, destaca-se o disposto no Parágrafo único do Artigo $3^{\circ}$ da Resolução: "os sistemas devem constituir e fazer funcionar um setor responsável pela educação especial, dotado de recursos humanos, materiais e financeiros que viabilizem e deem sustentação ao processo de construção da educação inclusiva".

A fim de concretizar essa proposta, no Plano Nacional de Educação (PNE) de 2001 (Lei no 10.172, 2001), o governo traçou objetivos e metas, a serem cumpridas no prazo de dez anos, relacionadas à formação de professores para o atendimento dos alunos da educação especial. No entanto, no ano de 2006, as habilitações específicas vinculadas à Pedagogia, foram extintas, inviabilizando, assim, que a meta 8.20 do PNE/2001 fosse implementada: inclusão ou ampliação, em especial nas universidades públicas, habilitação específica, em níveis de graduação e de pós-graduação, para formar pessoas especializadas em educação especial em cada unidade da Federação.

Novas políticas, linguística e educacional, começaram a ser delineadas para os alunos surdos, decorrente da luta empreendida pelas comunidades surdas desde 0 ano de 1996 a fim de assegurar seus direitos (Lodi, 2013). O primeiro fruto dessa luta deu-se com o reconhecimento da Libras (Lei $n^{\circ} 10.436,2002$ ), em 2002, e aproximadamente três anos e meio mais tarde, pelo Decreto $n^{\circ} 5.626 / 05$ (2005), que, em diálogo com as reivindicações das comunidades surdas, definiu e defendeu a educação bilíngue, assim como orientou em quais espaços ela deve ser implantada. Para viabilizar a formação linguística dos pedagogos e o conhecimento das particularidades da língua "falada" pelos alunos aos licenciados das áreas específicas, o Decreto determinou a inclusão da Libras como disciplina curricular obrigatória nos cursos de formação de professores, deixando, a cargo das instituições de ensino, a carga horária e o currículo mínimo a ser trabaIhado nesta disciplina. Além dessa formação, prevê-se ainda, para os pedagogos, a inclusão no currículo, de uma disciplina que aborde o ensino da modalidade escrita do português como segunda língua. Destas duas disposições, a única que vem sendo cumprida pelas instituições de educação superior, públicas e privadas, é o ensino da Libras.

No ano de 2007, com o objetivo de melhoria da educação básica foi lançado o Plano de Desenvolvimento da Edu- 
cação - PDE (Brasil, 2007), política que teve, como um dos principais pontos, a formação de professores e a valorização dos profissionais da educação. Foi criada, pela União, a Universidade Aberta do Brasil que, por meio da educação à distância, buscou expandir e interiorizar a oferta de cursos e programas de educação superior. No entanto, o PDE não apontou nenhuma especificidade quanto à formação de professores para a educação especial e nem para a educação de surdos.

A nova Política Nacional de Educação Especial na Perspectiva da Educação Inclusiva (Brasil, 2008), publicada no ano seguinte, reconheceu a educação inclusiva como uma ação política, social e pedagógica em defesa do direito de todos à educação, direcionando as ações da educação especial para o Atendimento Educacional Especializado AEE, responsável por disponibilizar recursos e serviços e orientar os processos de ensino e de aprendizagem dos alunos com deficiência nas salas regulares. Para a formação dos profissionais do AEE, prevê-se "formação, inicial e continuada, conhecimentos gerais para o exercício da docência e conhecimentos específicos da área" (Brasil, 2008, p.11), entre eles aqueles relacionados ao ensino da Libras.

No PNE de 2014, Lei nº 13.005 (2014), foi assegurada formação em nível superior a todos os profissionais da educação básica, obtida em cursos de licenciatura na área em que atuam (Meta 15); investimento em formação continuada, considerando as necessidades, demandas e contextos dos sistemas de ensino; e formação, na pós-graduação, a $50 \%$ dos professores (Meta 16). Nele, no entanto, nada consta sobre uma formação específica aos professores de surdos. Prevê-se, apenas, na estratégia 4.16, o incentivo à inclusão, nos cursos de licenciatura e nos demais cursos de formação para profissionais da educação, dos referenciais teóricos, das teorias de aprendizagem e dos processos de ensino-aprendizagem para o atendimento educacional dos alunos com deficiência, tratados de forma bastante genérica.

Frente a esse movimento político, este estudo teve como objetivo analisar, a partir de pesquisas produzidas na pós-graduação, discussões relativas à formação de professores de surdos no período de 1995 a 2014, momento de transformações significativas para o campo da educação de surdos.

\section{Procedimentos Metodológicos}

Este estudo constituiu-se em uma pesquisa bibliográfica que adotou, como procedimento metodológico, a Revisão Sistemática da Literatura. Para a busca das teses e dissertações, optou-se pela pesquisa nas bibliotecas virtuais das universidades que possuíam Programas de Pós-graduação em Educação. No entanto, frente à existência de 159 Programas, foi necessária nova delimitação das bases. Decidiu-se que a pesquisa seria realizada apenas nos Programas de Pós-graduação em Educação com conceito cinco ou superior, conforme avaliação da CAPES, ao se considerar serem esses programas, potencialmente, os mais antigos no país e, portanto, neles poderia estar concentrado um número maior de pesquisas.
A busca sistemática dos dados ocorreu entre agosto e outubro de 2014, a partir dos seguintes descritores: "formação de professores", "educação de surdos", "deficiência auditiva", "educação inclusiva", "deficiente auditivo", "educação especial”, surdos ${ }^{1}$, surdo, surdez e ensino. O descritor "formação de professores" foi o único utilizado de forma isolada e, posteriormente, mantido fixo para combinação com os demais por meio do comando AND. Foram encontrados 24.925 estudos. A grande concentração de pesquisas (15.955) ocorreu com o descritor "formação de professores" quando usado de forma isolada. Em relação à combinação de descritores, a que possibilitou um maior número de estudos foi "formação de professores" + "educação de surdos" (5.529), seguida pelas combinações "formação de professores" + surdez e "formação de professores" + surdo, ambas concentrando 1.242 trabalhos respectivamente. As combinações de detratores que menos estudos disponibilizaram foram "formação de professores" + ensino (91), "formação de professores" + "deficiente auditivo" (89), e por fim "formação de professores" + inclusão (26).

No processo de seleção dos trabalhos, observou-se que, muitas vezes, a temática tratada não era compatível com os objetivos deste estudo. Foi necessária, então, a aplicação dos critérios de inclusão - pesquisas que possibilitassem o acesso ao estudo na íntegra e cujos títulos e resumos abordassem temáticas que, potencialmente, estariam relacionadas com o tema desta pesquisa; e dos critérios de exclusão - pesquisas repetidas e estudos que versavam sobre outros temas. Chegou-se ao número de 59 dissertações e teses. Procedeu-se assim, à leitura completa das pesquisas.

No decorrer desta etapa, observou-se ainda que alguns estudos, em sua completude, discutiam temáticas que apenas tangenciavam o tema formação de professores de surdos. Foi, então, necessário aplicar, novamente, os critérios de inclusão e de exclusão. Compuseram o corpus definitivo desta pesquisa, 35 pesquisas (19 dissertações e 16 teses), sobre as quais recaiu a análise dos dados.

\section{Análise dos Dados}

A leitura dos trabalhos deixou entrever que as pesquisas abordavam a formação de professores a partir de dois eixos: os que discutiam as extintas habilitações específicas e os que abordaram a nova política. Neste último eixo, observou-se que as discussões voltavam-se ora para a formação inicial e ora para a formação continuada, razão pela qual foram tecidas discussões separadas sobre estes processos.

\section{As extintas habilitações específicas}

Dois trabalhos, escritos em 2004 e em 2009, discutiram a formação realizada nas habilitações em EDAC. No primeiro, escrito em 2004, Rampelotto teceu severas críticas

1 Foram usadas aspas apenas para os descritores formados por mais de uma palavra 
em relação à formação nelas oferecida, dado o contexto histórico em que foram pensadas e propostas (década de 1970). Seu currículo era marcado por uma concepção de surdo como sujeito que precisaria ser reabilitado a fim de se tornar ou se aproximar do modelo de normalidade ouvinte. Assim, a formação oferecida aos futuros professores, ao invés de voltar-se para um trabalho que possibilitasse ao surdo seu desenvolvimento pedagógico, centrava-se na utilização de métodos que visavam o desenvolvimento da fala dos estudantes.

A despeito dos problemas existentes nas habilitações, Silva (2009) apontou que, com sua extinção, teve início um período no qual não se tiveram orientações claras sobre como deveria ocorrer os processos formativos de professores para atuar com surdos. Para Silva (2009), a falta de uma política específica de formação inicial e continuada para esta formação, acabou por transformá-la em uma especialização, realizada em cursos construídos a partir de conteúdos voltados à formação geral que, no melhor dos casos, garantiu uma formação benéfica apenas para o docente generalista, mas não para o especialista. Esta formação, muitas vezes, acabou por restringir-se ao ensino da Libras, com carga horária ínfima, como se fosse possível aprender uma língua e utilizá-la em toda sua dimensão discursiva, em cursos de curta-duração.

\section{A nova configuração para a formação do professor: a educação inclusiva}

Foram encontrados trabalhos que se dedicaram a estudar como os cursos de formação inicial de professores tem se organizado, potencialmente e na prática, a fim de se garantir, aos futuros docentes, práticas que contemplem a diversidade linguística dos alunos surdos. Outros voltaram seu olhar para a formação continuada. Visando uma melhor divisão das discussões, foram indicadas seções separadas para estas formações.

\section{Formação inicial}

Algumas pesquisas tiveram com objeto de estudo a formação hoje oferecida pelas universidades brasileiras. Para Alves (2010), que analisou o currículo de um curso de Pedagogia em uma instituição do interior do Estado do Rio de Janeiro, a nova formação de professores pode favorecer, pelo menos potencialmente, um processo formativo multiculturalmente orientado, desde que esta valorize a pluralidade cultural dos alunos e promova reflexões que venham a questionar as relações de poder responsáveis pela produção de desigualdades, estereótipos e preconceitos. Esta visão da autora vai ao encontro da condição que deveria ser oferecida aos surdos no espaço escolar, desde que reconhecidos a partir da diversidade social, cultural e linguística deles constitutiva. No entanto, as análises realizadas apontaram o contrário, na medida em que os aspectos multiculturais têm tido pouca importância nos cursos e, quando ocorrem, aparecem de forma desvinculada da prática. Os currículos são construídos a partir de uma somatória desarticulada de disciplinas, fato que demonstra pouca clareza sobre as necessidades formativas impostas hoje a um professor frente à diversidade constitutiva das salas de aula.

Movimento muito próximo pode ser observado na pesquisa de Macedo (2010), que buscou compreender de que maneira a Política Nacional de Educação Especial tem se materializado nos Cursos de Pedagogia, principalmente no que diz respeito às dimensões conceitual, filosófica, cultural, política e metodológica da educação especial e da inclusão escolar. A partir da análise do Projeto Político Pedagógico, da grade curricular e das ementas das disciplinas em cursos de pedagogia oferecidos nas Universidades Estaduais paulistas, percebeu-seque alguns princípios da Política têm se materializado de forma reduzida, em discussões realizadas em um único semestre e, em algumas vezes, de forma optativa. Esta mesma constatação foi realizada por Decker (2006), que também concluiu que as discussões relativas aos alunos da educação especial têm sido realizadas de forma dissociada das demais disciplinas.

Quanto à formação de professores de surdos, Macedo (2010) concluiu que se restringe à apresentação da Libras aos licenciandos e a uma discussão que se volta para "sua importância para o desenvolvimento e aquisição da linguagem de alunos surdos incluídos nas salas de ensino regular" (p.110). Pouco ou nada é trabalhado sobre o aspecto pedagógico propriamente dito. E muito embora se assista à criação de programas e políticas que visam assegurar o direito à diversidade nos sistemas educacionais brasileiros, o que se observa hoje, na prática, é apenas a garantia do acesso dos alunos ao sistema, mas não sua permanência, na medida em que o professor continua sendo formado para atuar a partir de outra perspectiva de educação e de concepção de alunos (Decker, 2006).

Menezes (2008), nesse mesmo contexto, apresentou aspectos que, a seu ver, seriam fundamentais nos processos formativos, mas que, infelizmente, pouco espaço tem recebido nos cursos de graduação: reflexões sobre o conceito de inclusão, da diversidade dos estudantes e das dificuldades e facilidades inerentes aos processos escolares. Destaque, no caso dos surdos, deveria haver uma revisão de conceitos que perpassam concepções de aluno, língua e educação, defendendo, para este processo, a necessária formação docente bilíngue, única forma de serem contempladas as especificidades educacionais deste grupo de alunos. Para Soares (2013), frente à condição bilíngue dos surdos, logo, de sua educação, o professor deve ter uma formação que, em muitos aspectos, se assemelha à do professor de ensino de línguas estrangeiras. Para a autora, a formação deve propiciar o conhecimento e a vivência da e na Libras, embora reconheça que apenas esse aspecto não é suficiente para as práticas escolares.

Pode-se dizer que os trabalhos aqui referenciados e outros que, por realizarem discussões muito próximas, tiveram suas vozes presentes no tecer das discussões, apontaram que formação inicial de professores não tem 
contemplado as especificidades pedagógicas relativas à educação de surdos e, em consonância com os pressupostos que sustentam a Política de Educação Especial, muitas vezes, saber um pouco de Libras torna-se suficiente para se lidar com os processos educacionais destes alunos, visão esta que atribui à Libras caráter instrumental, deslocando-a de sua condição linguística (Lodi, 2013). Nesse sentido, os desafios para esta formação aumentam, se a proposta for uma educação em equidade entre surdos e ouvintes.

\section{Formação continuada: práticas presenciais realizadas em serviço}

As pesquisas que abordaram a formação continuada discutiram, em sua maioria, a formação do professor regente, realizada em serviço, por considerarem que a formação inicial não está atendendo as necessidades dos alunos surdos. De forma mais discreta, foram encontrados estudos voltados à formação do professor especialista (atuação no AEE).

No que diz respeito à formação do professor regente para atuar com alunos surdos incluídos em salas de ouvintes, Zanata (2004) defendeu que esta deveria envolver estratégias de ensino, visando um processo contínuo de ações e reflexões, por meio de programas colaborativos de formação continuada, realizados em serviço, no ambiente escolar,a fim de ser possível que os professores reflitam sobre as práticas pedagógicas, tornando-se, gradualmente, independentes para o desenvolvimento dos processos educacionais. Esta forma de se compreender a formação dos professores foi observada também nos estudos de Menezes (2008) e de Morais (2009), que defenderam uma formação não especializada em apenas uma diferença, mas sim que envolvessem a todos os alunos com deficiência. Segundo Morais (2009), esta formação torna-se necessária a fim de ser possível pensar processos de ensino e de aprendizagem que ampliem as possibilidades de apropriação do conhecimento, tanto do aluno quanto do professor, minimizando, com isso, os altos índices de reprovação e/ou desistência destes alunos, quando incluídos na rede regular de ensino. Posicionamento distinto à esse foi encontrado no estudo de Tosta (2014), que defendeu uma formação específica aos professores, se possível, realizada por centros de atendimento especializados. A proposta defendida por ela deve partir do pressuposto de que os professores deveriam saber Libras para atuar junto aos alunos surdos.

Destacou-se ainda, em alguns trabalhos analisados, a dificuldade de se realizar formações consistentes para a atuação do professor de surdos ao se considerar os aspectos políticos que envolvem o olhar para estes alunos. Reconheceu-se que, apesar de algumas conquistas políticas por parte da comunidade surda, seus membros ainda são vistos pela legislação brasileira como deficientes e, portanto, desconsidera-se que eles pertencem a uma comunidade cultural e linguística minoritária. Segundo Soares (2013), a comunidade surda, ainda hoje, sofre com a invisibilidade política a que sempre esteve sujeita, na medida em que o
Poder Público continua negligenciando seu direito à educação bilíngue ao submetê-los a uma educação pensada e organizada para alunos ouvintes. Nessa mesma direção seguiu a pesquisa de Buiatti (2013), para quem as questões que perpassam a inclusão ainda são pautas que devem ser enfrentadas por todos, principalmente no que diz respeito à formação continuada de professores.

Vaz (2013), por defender os processos educacionais inclusivos, acredita em uma formação específica apenas para os professores do AEE, por reconhecer ser de responsabilidade destes profissionais a formação continuada dos professores regentes, posição também assumida por Possa (2013). No entanto, essa autora apresenta uma realidade não considerada nas pesquisas: uma formação inicial especializada realizada em cursos de licenciatura em educação especial. Para a autora, nestes cursos preveem-se ações para a formação de professores que podem vir a assegurar a inclusão de todos os alunos no sistema regular. No entanto, no que diz respeito aos surdos, a autora ressalta que o professor do AEE deve ser bilíngue e conhecer modelos metodológicos que orientem a conduta pedagógica em sala e no AEE, a fim de haver a participação de todos nos processos educacionais.

Nota-se assim na maioria das pesquisas, uma preocupação com a formação de professores com vistas a ser garantida a inclusão escolar dos alunos surdos e não para o desenvolvimento de práticas bilíngues no contexto escolar; posição contrária a esta foi observada na pesquisa de Hubner (2006), que defendeu que os processos educacionais de surdos devam ser realizados em salas exclusivas em escolas-polo para surdos, única possibilidade de os alunos surdos serem olhados a partir de sua especificidade linguística e sociocultural e terem sua educação realizada por professores bilíngues, por meio de práticas pedagógicas construídas a partir das peculiaridades da Libras.

Esta forma de se compreender os surdos e sua educação foi encontrada também no trabalho de Braga (2006), que reconheceu, como diferencial na formação, o reconhecimento do potencial surdo para a aprendizagem e para a construção do conhecimento; por isso, é de fundamental importância que surdos participem dos processos formativos dos professores, realizada de forma continua e partir de uma ótica multicultural.

\section{Formação continuada: práticas desenvolvidas à distância (EaD)}

As possibilidades de formação continuada de professores para a educação de surdos se ampliaram com a implantação de cursos EaD. Dal-Forno (2009) discutiu, em sua pesquisa, as contribuições e limites de um programa de desenvolvimento profissional à distância, revelando ser, de fundamental importância, que nestes se invista também na formação pedagógica dos formadores, entendida como o conhecimento das técnicas didáticas, estrutura de aulas, planejamento de ensino, teorias do desenvolvimento huma- 
no, planejamento curricular, conhecimento do conteúdo a ser ensinado e do contexto em que os formando atuam. Para a autora, a formação de professores a partir de 2008, tornou-se um ponto nevrálgico, à medida que a formação inicial não é suficiente para a realidade educacional do Brasil. Para Dal-Forno (2009), antes de a legislação tornar obrigatória a inclusão de alunos em salas regulares, deveria ter havido investimento prévio na formação dos educadores de modo a prepará-los para esta nova realidade.

Complementando e, ao mesmo tempo, corroborando com as discussões realizadas por Dal-Forno (2009), Tsukamoto (2010), ao abordar uma proposta de formação continuada realizada em um ambiente virtual de aprendizagem, afirmou que é muito importante que se assegure, na formação inicial, um olhar para a educação inclusiva na educação básica que se distancie da visão histórica da educação especial, na qual os surdos eram olhados a partir do enfoque clínico de reabilitação, para, posteriormente, ser possível se pensar em uma formação específica. A pesquisa de Tsukamoto (2010) apontou o pouco conhecimento dos professores sobre cultura surda e a não compreensão de que a Libras é a língua que possibilita aos surdos o pleno desenvolvimento linguístico-cognitivo-sócio-cultural, tornando-se, portanto, o elemento unificador para o processo educacional e para a aprendizagem da segunda língua: o português escrito.

Nesta mesma direção, a pesquisa de Mourão (2009) analisou um curso virtual de Libras, entendido como ferramenta importante para a formação continuada de professores. Para a autora, as conquistas dos surdos precisam ser traduzidas em ações que permitam o acesso a uma educação de qualidade, transcendendo uma leitura pautada em adaptações curriculares. Para ela torna-se necessário que haja uma mudança ideológica na forma de se compreender os surdos, cujos reflexos poderão ser sentidos na prática pedagógica; por isso deve ser, portanto, propiciada uma formação teórica e prática, a começar pela Libras. Uma das contribuições da pesquisa foi a oferta de um espaço para a reflexão e discussão, junto aos profissionais da educação de várias regiões do país, sobre uma proposta de formação por meio da Libras EaD. Para Mourão (2009), os professores preocupam-se com a formação e buscam discussões teóricas que contribuam com sua atuação; no entanto, acreditam que apenas sabendo Libras as questões relativas ao ensino do aluno surdo seriam solucionadas.

Observa-se assim nestas pesquisas, que o avanço tecnológico dos últimos anos possibilitou formas novas de se pensar e propor processos de formação continuada aos professores.

\section{Considerações}

As pesquisas analisadas apontaram para formas distintas de se pensar a formação de professores de surdos; no entanto, observa-se, nelas, a existência de um ponto de convergência: a formação inicial oferecida hoje aos professores não tem sido suficiente para a formação de um profes- sor que deve atender a diversidade constitutiva das escolas brasileiras, fato que se agrava quando esta é caracterizada pelo uso de uma língua não compartilhada entre professor e alunos e entre todos os alunos, como é o caso dos alunos surdos. Reconhece-se que apesar das transformações políticas ocorridas nas duas últimas décadas, a formação inicial pouca transformação sofreu. Assim, discussões envolvendo a educação especial (quando presentes nos cursos) e a educação de surdos (no caso a disciplina Libras, único espaço destinado a esta temática, obrigatória nos cursos por força de Lei), ocorrem de forma isolada das demais disciplinas e descontextualizada da realidade escolar. Pode-se dizer, portanto, que a formação inicial reflete uma problemática histórica em nosso país relativa ao descompromisso com a educação, materializada no pouco investimento, na pouca valorização do profissional e na compreensão superficial demonstrada, no decorrer da história, sobre aos saberes intrínsecos às práticas pedagógicas, e, no caso dos surdos, a desconsideração deste grupo de alunos como constitutivos de um grupo sociocultural e linguístico minoritário.

Para parte dos pesquisadores, a formação dos professores deveria ser específica, por se defender uma educação em salas exclusivas para surdos, que possibilitariam uma educação em Libras, logo bilíngue. Este posicionamento contrapõe-se a um número significativo de pesquisas que defendem uma formação não especializada, voltada para conhecimentos gerais sobre educação especial, à medida que se acredita que a educação dos surdos deva ocorrer nas salas regulares de ensino, visão que corrobora com a leitura dos surdos com deficientes. As especificidades linguísticas destes alunos tornam-se, portanto, de responsabilidade do professor especialista.

Observou-se, no entanto, que alguns trabalhos que defenderam uma formação específica, fizeram-no a partir de processos de formação continuada que se centravam no ensino da Libras. Estes posicionamentos reiteram a crítica realizada por Lodi (2013) com relação ao tratamento dado, de forma velada, à Libras, pela Política de Educação Especial e em outros documentos legais do Brasil: o de servir como instrumento para a educação dos surdos, destituída de seu status linguístico, de sua relação intrínseca com a cultura e com os processos de subjetivação humanos. Pode-se inferir que com a maior visibilidade da Libras nas esferas sociais (entre elas a educacional) pouca reflexão tem sido realizada sobre o papel que esta língua tem na educação dos surdos, dos processos implicados em sua aprendizagem pelos professores, mas principalmente, de ser ela a base para se pensar práticas pedagógicas que respeitem os alunos surdos.

Como conclusão, não se pode deixar de destacar o papel que a academia exerce em todo este processo, na medida em que é neste espaço que deve ser possibilitado o acolhimento ao novo, do que está presente em cada aluno, das diferenças constitutivas da sociedade brasileira. Um espaço que deve estar comprometido política, cultural e socialmente, produzindo novos sentidos aos processos educacionais dos alunos brasileiros. Reconhece-se que ainda há muito a se estudar e a se fazer, principalmente, no que 
se refere aos surdos, seus processos escolares e, portanto, nos aspectos formativos do principal agente desta educação: os professores.

\section{Referências}

Alves, M.R.F. (2010). Multiculturalismo e formação de professores: um estudo das Diretrizes Curriculares Nacionais para o Curso de Pedagogia. Tese de Doutorado em Educação, Faculdade de Educação, Universidade Federal do Rio de Janeiro, Rio de Janeiro, RJ.

Braga, R.M.C. (2006). Para além do silêncio: outros olhares sobre a surdez e a educação de surdos. Dissertação de Mestrado em Educação, Universidade do Vale do Rio dos Sinos, São Leopoldo.

Brasil. Ministério da Educação. (2007). O Plano de Desenvolvimento da Educação: razões, princípios e programas. Brasília, DF: MEC. Recuperado: 10 jun. 2016. Disponível: http://www.gestaoescolar. diaadia.pr.gov.br/arquivos/File/pdf/pde.pdf.

Brasil. Ministério da Educação (2008).Política Nacional de Educação Especial na Perspectiva da Educação Inclusiva.Brasília: MEC/ SEESP. Recuperado: 1 mai. 2016.Disponível: http://portal.mec. gov.br/arquivos/pdf/politicaeducespecial.pdf.

Buiatti, V.P. (2013). Atendimento educacional especializado: dimensão política, formação docente e concepções dos profissionais. Tese de Doutorado em Educação, Universidade Federal de Uberlândia, Uberlândia.

Dal-Forno, J.P. (2009). Formação de formadores e educação inclusiva: análise de uma experiência via internet. Tese de Doutorado em Educação, Universidade Federal de São Carlos, São Carlos.

Decker, A. (2006). Inclusão: O Currículo na Formação de Professores. Dissertação de Mestrado em Educação, Universidade do Vale do Rio dos Sinos, São Leopoldo.

Decreto 5.626, de 22 de dezembro de 2005 (2005, 22 de dezembro). Regulamenta a Lei no 10.436, de 24 de abril de 2002, que dispõe sobre a Língua Brasileira de Sinais - Libras, e o art. 18 da Lei no 10.098, de 19 de dezembro de 2000. Disponível: http://www. planalto.gov.br/ccivil_03/_ato2004-2006/2005/decreto/d5626.htm. Recuperado: 10 jun. 2016.

Hubner, C.A.R. (2006). A Formação dos Professores da EscolaPólo Estadual de Educação para Surdos na Regional de São José - Santa Catarina. Dissertação de Mestrado em Educação, Universidade Federal de Santa Catarina, Florianópolis.

Lei $n^{\circ}$ 4.024, de 20 de dezembro de 1961(1961, 20 de dezembro). Fixa as Diretrizes e Bases da Educação Nacional. Recuperado: 1 mai. 2016.Disponível: http://www.planalto.gov.br/CCIVIL_03/leis/ L4024.htm.
Lei n. ${ }^{\circ}$ 9.394, de 20 de dezembro de 1996 (1996, 20 de dezembro). Estabelece as diretrizes e bases da educação nacional. Brasília: Diário Oficial da União. Recuperado: 1 jan. 2016. Disponível: http://www.planalto.gov.br/ccivil_03/Leis/L9394.htm.

Lei $n^{\circ}$ 10.172, de 9 de janeiro de 2001(2001, 9 de janeiro).Plano Nacional de Educação. Recuperado: 1 junho de 2016. Disponível: http://www.planalto.gov.br/ccivil_03/leis/leis_2001/l10172.htm.

Lei $n^{\circ}$ 10.436, de 24 de abril de 2002 (2002, 24 de abril). Dispõe sobre a Língua Brasileira de Sinais - Libras. Recuperado: 1 jun. 2016. Disponível: http://www.planalto.gov.br/ccivil_03/leis/2002/10436.htm.

Lei $n^{\circ}$ 13.005, de 25 de junho de 2014(2014, 25 de junho).Aprova o Plano Nacional de Educação (PNE) e dá outras providências. Brasília. Recuperado: 10 jun. 2016. Disponível: http://www. observatoriodopne.org.br/uploads/reference/file/439/documentoreferencia.pdf.

Lodi. A.C.B. (2013). Educação bilíngue para surdos e inclusão segundo a Política Nacional de Educação Especial e o Decreto $n^{\circ}$ 5.626/05. Educação e Pesquisa, 39, 49-63.

Lodi. A.C.B. (2014). Declaraciones de UNESCO, educación de sordos y educación inclusiva: un analisis de la politica nacional de educación de Brasil. Psicología, Conocimiento y Sociedad, 4, 261-294.

Macedo, N.N. (2010). Formação de professores para a educação inclusiva nos cursos de Pedagogia das Universidades Públicas Paulistas.Dissertação de Mestrado em Educação Especial, Universidade Federal de São Carlos.

Menezes, M.A. (2008). Formação de Professores de Alunos com Necessidades Educacionais Especiais no Ensino Regular. Tese de Doutorado em Educação, Pontifícia Universidade Católica de São Paulo, São Paulo.

Morais, M.C.F.Z.B. (2009). Os Caminhos da Formação Continuada na Rede Municipal de Ensino de Curitiba. Dissertação de Mestrado em Educação, Universidade Federal do Paraná, Curitiba.

Mourão, M.P. (2009). Ensino da língua brasileira de sinais e formação de professores à distância. Dissertação de Mestrado em Educação, Universidade Federal de Uberlândia, Uberlândia.

Pereira, M.C.C. (2000). Formação de Profissionais na área da surdez na Pontifícia Universidade Católica de São Paulo. In: Seminário Surdez: Desafios para o próximo milênio, Anais do Seminário Surdez: Desafios para o próximo milênio (pp. 128-132). Rio de Janeiro. Recuperado: 1 jun. 2016.Disponível: http://www. dominiopublico.gov.br/download/texto/me002965.pdf.

Possa, L.B. (2013). Formação em Educação Especial na UFSM: Estratégias e Modos de Constituir-se Professor. Tese de Doutorado em Educação, Universidade Federal de Santa Maria, Santa Maria. 
Rampelotto, E.M. (2004). Mesmidade ouvinte \& alteridade surda: invenções do outro surdo no Curso de Educação Especial da Universidade Federal de Santa Maria. Tese de Doutorado em Educação, Universidade Federal do Rio Grande do Sul, Porto Alegre.

Resolução CNE/CEB 2/2001 de11 de setembro de 2001 (2001, 11 de setembro). Institui Diretrizes Nacionais para a Educação Especial na Educação Básica. Brasília, DF: Diário Oficial da União, Seção 1E, p. 39-40. Recuperado: 1 jun. 2016.Disponível: http://portal. mec.gov.br/cne/arquivos/pdf/CEB0201.pdf. Silva, E. (2009). Formação de professores em educação especial: a experiência da UNESP - Campus de Marília. Dissertação de Mestrado em Educação, Faculdade de Filosofia e Ciências, Universidade Estadual Paulista, Marília.

Soares, R.S. (2013). Educação bilíngue de surdos: desafios para a formação de professores. Dissertação de Mestrado em Educação, Faculdade de Educação, Universidade de São Paulo, São Paulo.

Tosta, E.I.L. (2014). Educação Especial em Mato Grosso: trajetórias e políticas públicas na rede estadual de ensino (1962- 2012). Tese de Doutorado em Educação, Universidade Federal do Rio Grande do Sul, Porto Alegre.

Tsukamoto, N.M.S. (2010). Educação Inclusiva em ambiente virtual de aprendizagem: uma proposta para a formação de professores. Dissertação de Mestrado em Educação, Pontifícia Universidade Católica do Paraná, Curitiba.

Vaz, K. (2013). O professor de educação especial nas políticas de perspectiva inclusiva no Brasil: concepções em disputa. Dissertação de Mestrado em Educação, Universidade Federal de Santa Catarina, Florianópolis.

Zanata, E.M. (2004). Práticas pedagógicas inclusivas para alunos surdos numa perspectiva colaborativa. Doutorado em Educação Especial, Universidade Federal de São Carlos, São Carlos.

License information: This is an open-access article distributed under the terms of the Creative Commons Attribution License (type CCBY), which permits unrestricted use,distribution and reproduction in any medium, provided the original article is properly cited.

\section{Sobre as autoras}

Melaine Duarte Ribeiro Muttão (melmutton@yahoo.com.br).

Pedagoga e Mestre em Educação pela Faculdade de Filosofia, Ciências e Letras de Ribeirão Preto da Universidade de São Paulo. Ribeirão Preto- SP. https://orcid.org/0000-0001-8797-6724

Ana Claudia Baliero Lodi (analodi@ffclrp.usp.br)

Livre-docente em Educação pela Faculdade de Filosofia, Ciências e Letras de Ribeirão Preto da Universidade de São Paulo. Docente do Departamento de Educação, Informação e Comunicação e do Programa de Pós-graduação em Educação da Faculdade de Filosofia, Ciências e Letras de Ribeirão Preto da Universidade de São Paulo (FFCLRP/USP). Ribeirão Preto- SP. https://orcid.org/0000-0002-7106-172X 